\title{
THE RELATIONSHIP BETWEEN PERSONALITY TYPE AND LEADERSHIP FOCUS
}

\author{
GRANT SIEFF \\ grant@infochoice.co.za \\ LOUIS CARSTENS \\ Department of Human Resources Management \\ University of Johannesburg
}

\begin{abstract}
Optimising focus is a key success driver for many organisation leaders. The relationship between personality type and leadership focus is examined. Personality type is assessed with Form $\mathrm{M}$ of the Myers-Briggs Type Indicator instrument, and leadership focus is explored through the development and application of a Leadership Focus Questionnaire. South African executives form the target population for this study. Both functionalist and interpretive approaches are applied. Three primary theoretical hypotheses about leadership focus, concerning (1) optimising the balance of focus between external and internal priorities, (2) the fit between the leadership personality type and the organisation type, and (3) the capacity to manage a multiple focus, are considered. Results show that Extraverted personality types are more comfortable with the challenges of focus in the leadership role than are Introverted types, and Extraverted, Sensing, Thinking and Judging types experience a greater degree of fit with their organisations than do Introverted, Intuitive, Feeling and Perceiving types.
\end{abstract}

Key words

Personality type, leadership

The role of the organisation leader requires by most definitions a multifold focus across the various elements of the organisation and the environment within which the organisation operates. The effective leader is expected to address stakeholder needs, be an agent of change, instill followership amongst staff, and set the course for the organisation. To realise these expectations, the organisation leader must manage both the complexity of trends, shocks and uncertainties in the external environment that may affect the organisation, and the internal human and organisational dynamics that will maximise organisation potential.

A number of skill-sets are needed for the leader to be able to manage such complexity. Moreover, a meta-skill may need to be evident to achieve the most appropriate balance of focus across the various areas demanding leadership attention. Leadership skills can be considered in two broad categories (Patterson, Grenny, McMillan and Switzler, 1996). Firstly, there are those skills concerning what happens within the organisation. These internal factors include managing and motivating people, organising staff into effective structures, communicating direction, and developing or recruiting the necessary skills required for organisation effectiveness. Then there are the skills necessary to notice, understand and respond to the various external factors that affect the organisation. These factors may include developments in the areas of technology, government, environment, society and the economy. They are also likely to include global trends, shocks and uncertainties, as well as competitor responses to the external environment.

It has become common parlance in the arena of business leadership that leadership is a multiple. Most organisations of substance have an executive team and/or a board that work together to lead and direct the organisation's activities. The effective leader leverages this team and delegates effectively in order to best compensate for those leadership attributes that are subordinate or weaker in that leader's personality and competency make-up. Such leveraging and delegation most likely demonstrates a meta-skill of the effective business leader.

The problem of managing complex choices and achieving balance as a leader needs to be considered seriously, for the sake of both effective leadership and economic growth, for the general wellbeing of leaders across organisations, and for the quality of the organisational environment in general across organisations.

Self-awareness and self-management are important attributes for leadership success. A greater awareness of personality type and operational style will assist leaders to understand their behaviour preferences in addressing the complexity of decision making choices and the focusing of energy and attention. In discovering more about the nature of issues that each leader prefers to address, better choices may be made by the leader about 1) prioritising strategic focus areas, 2) allocation of time to various internal and external matters, and 3) enlisting support staff with complementary strengths. Organisation effectiveness may be enhanced through attention to 1) personal development for the leader, 2) the most appropriate delegation of responsibility to a leadership team, and 3) the organisation type most suited to the leader.

The research problem concerns how best to address the challenges of optimising focus and managing risk that is inherent in strategic leadership. These challenges can be encapsulated by a three-fold definition of the problem. Firstly, the personality type of the leader affects his or her approach to most effectively balance the focus on external versus internal factors in decision-making. Secondly, the personality type of a leader can influence his or her effectiveness, depending on organisation type. Thirdly, strategic leaders must demonstrate behavioural preferences that allow for a multiple focus in managing complex choices. A number of moderating variables need to be considered in relation to each of these three primary hypotheses, as is illustrated in Figures 1, 2 and 3.

The research aims to provide insight for leaders to identify where they may lack sufficient focus, and what actions they need to take to optimise their balance of focus. The qualities of strategic leadership depend on the leader developing such awareness in both thought and action.

The complexity of leadership has been explored extensively in the literature, with particular reference to the role of personality. Research areas into leadership personality have included, amongst others

- capacity for cognitive complexity (Boal and Hooijberg, 2001)

- style diversity (Shelton, Mckenna and Darling, 2002; Politis, 2003; Gill, 2004) 
- building a cohesive culture (Shelton et al., 2002; Schein, 1985)

- forming successful and sustainable relationships (Testa, 2002; Weymes, 2003)

- achieving congruence between self and stakeholder perceptions (Testa, 2002)

- personal effectiveness (Klagge, 1996; Kets de Vries, 2001)

- ability to balance conflicting priorities (Patterson et al., 1996)

- capacity to transform (Barling, Slater and Kelloway, 2000; Carless, 2001; Denton and Vloeberghs, 2003)

- traits, such as humility and determination (Collins, 2001).

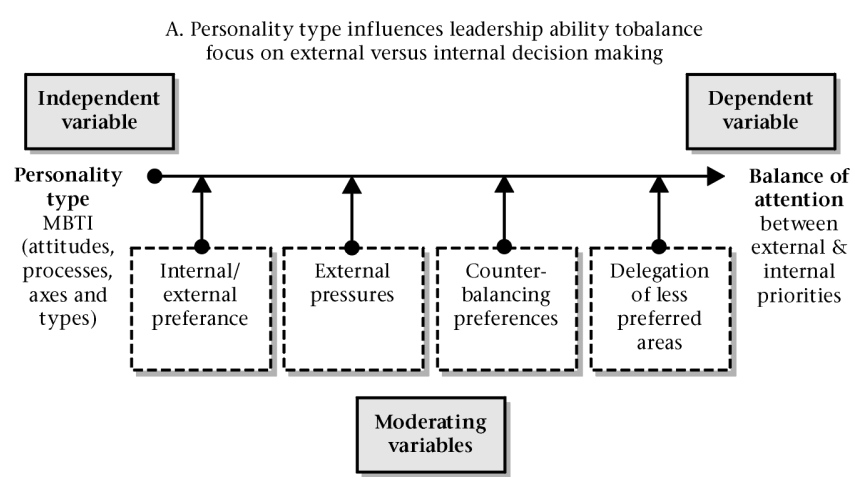

Figure 1: Primary hypothesis one

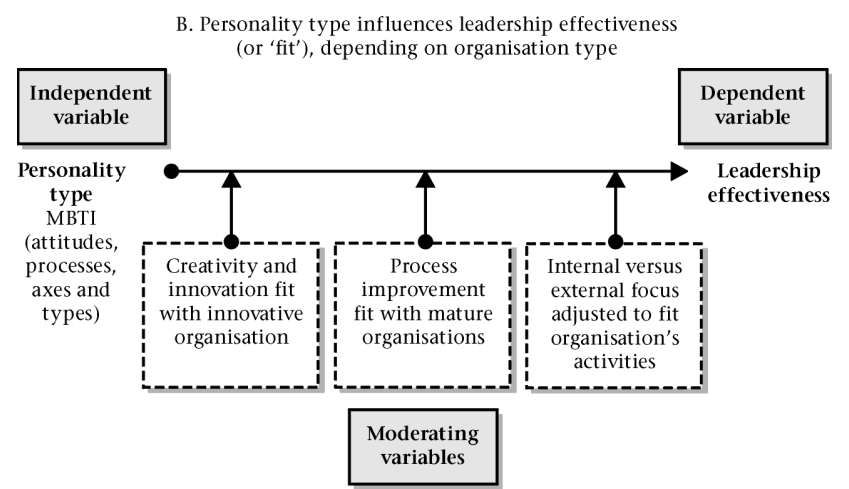

Figure 2: Primary hypothesis two

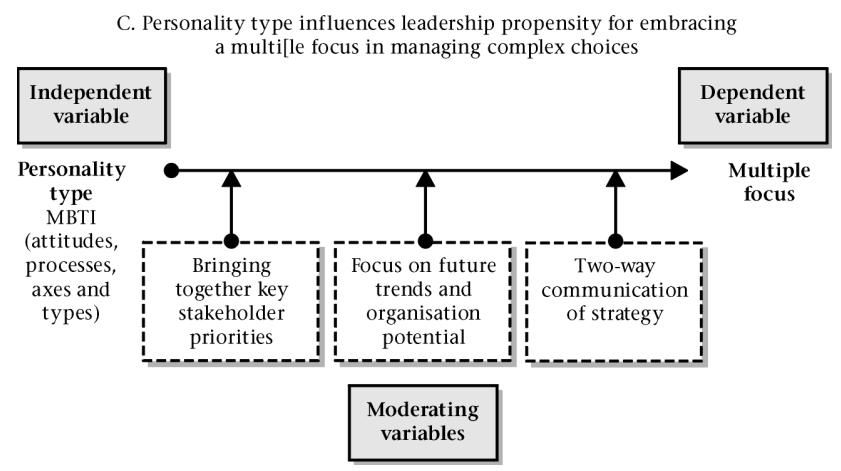

Figure 3: Primary hypothesis three

While no one framework can yet claim to offer an incontestably definitive basis for understanding the personality of a leader, Jungian personality theory, incorporating the following three pervasive principles, provides a basis for understanding the complexity of leadership: 1) the principle of opposites - every wish immediately suggests its opposite; 2) the principle of equivalence - the energy created from opposition is shared equally by both sides; and 3) the principle of entropy - the tendency for oppositions to come together, and for energy to decrease over a person's lifetime.

These three principles implicitly recognise the complexity of personality and the related dilemmas that inevitably arise around the tensions of opposites and the wisdom of balance. The Myers-Briggs Type Indicator ${ }^{\circledR}$ assessment methodology that arises from Jungian theory provides a means to understand some of this complexity.

Fitzgerald and Kirby (1997) note that the Myers-Briggs Type Indicator instrument has become an important tool to assist in valuing and understanding how to take best advantage of diversity and understand and value differences, because:

(® Myers-Briggs Type Indicator, Myers-Briggs, MBTI, and Introduction to Type are trademarks or registered trademarks of the Myers-Briggs Type Indicator Trust in the United States and other countries.)

1) the workplace is becoming increasingly diverse;

2) there continues to be both expansion in scope and refinement in focus of target markets;

3) the tendency to reduce staff and need to deal with higher stakeholder expectations requires high performance levels, best achieved through recognising individual uniqueness; and

4) organisations are becoming more internally complex to deal with increasingly complex external environments.

With regard to point four, above, internal complexity is better managed with a perspective on valuing and accommodating differences, which is facilitated by the Myers-Briggs Type Indicator instrument.

The Myers-Briggs Type Indicator instrument considers four separate dichotomies of individual personality type, namely: 1) Extraversion (E) versus Introversion (I); 2) Sensing (S) versus Intuition (N); 3) Thinking (T) versus Feeling (F); and 4) Judging (J) versus Perceiving $(\mathrm{P})$

For each of these dichotomies, an individual is assumed to have a preference for one of each pair of opposites over the other. With the Myers-Briggs Type Indicator instrument, “... the four preferences direct the characteristic use of perception and judgment by an individual ... (and) ... affect not only what is attended to in any given situation but also how conclusions are drawn about what has been perceived" (Myers, McCaulley, Quenk, and Hammer, 1998, p6).

The concept of strategic leadership extends beyond the personality of the leader. It has been linked to strategic thinking, strategic planning and strategic alignment. It is a concept also associated with the management of balance, focus, context and complexity. The focus on complexity has included addressing issues of uncertainty, and tools such as force-field analysis. A self-awareness relationship to strategic leadership has also been suggested, particularly in relation to 'whole-brain' thinking and 360 degree assessments. Sieff and Nurick (1997) have linked the role of strategic leadership to that of the integrator, with the responsibility of integrating the complex and disparate elements of stakeholder needs, while planning for the future and managing in the present.

Literature supporting the three primary hypotheses relating to leadership focus can be summarised as follows:

\section{Optimising the Balance of Focus between Internal and} External Factors

A recurring theme in the literature (Holt and Self, 2003; Testa, 2002; May, 1999; Gregersen, Morrison and Black, 1998) is the need to balance competing demands from internal and external factors. 360-degree tools are proposed to assist leaders to discover their gaps and blind spots to improve this balance. Attributes of strategic global leaders who do optimise balance include inquisitiveness, staying connected to employees, integrity, ability to manage uncertainty, ability to balance tensions, and business and organisational savvy (Gregersen et al.). Other attributes that facilitate an optimal balance in relation to change are 'appropriateness' and 'extrinsic valence' 
(expectation that external factors would have an influence on the respondent) (Holt et al.).

\section{Leadership Fit with Organisation Culture and Type}

The literature contains much that links leadership with organisation culture and organisation type (Chorn, 2004; Block, 2003; Hartley, 2002; Bridges, 2000; Lok and Crawford, 1998). This link is considered in a number of forms, including inquiries into subcultures, country cultures, the relationship between culture, type and commitment, role modeling and culture, culture and ethics and a culture of education. This study postulates that leadership personality type can have a greater or lesser fit with organisation type and culture, and that the degree of fit can influence the effectiveness of the leader in acting strategically to optimise the balance of focus.

In building a link between personality type and organisation type in the context of this study, it must be noted that the theoretical basis for the Myers-Briggs Type Indicator instrument has been applied to organisations as well as individuals (Chorn, 2004; Bridges, 2000). Bridges (2000) used the Myers-Briggs Type Indicator instrument in its current form to categorise organisational types, where, for example:

1) extraverted organisations look outward, creating strategies driven by market forces, while introverted organisations typically look inward, organising strategy around internal core competencies or leadership values;

2) sensing organisations are attuned to the concrete details and tried-and-true realities of the business, while intuitive organisations are more interested in the big picture and possibilities;

3) thinking organisations use objective principles and logical analysis, while feeling organisations make decisions based primarily on the personal values of the people involved; and

4) judging organisations deal with the external environment by preferring to reach closure and place great value in firm decisions, while perceiving organisations consider the external environment by placing more emphasis on discussion, flexibility, and the ability to gather additional information.

Chorn (2004, 1987) developed a strategic alignment framework that considers the leadership function as one of four main elements of an organisation (the others being culture, strategy and the operating environment). This strategic alignment framework provides a basis for considering the behaviour of groups of people, rather than individuals. Leadership success in this framework is associated with efforts to bring the four elements into alignment, given the premise that organisation effectiveness depends on alignment. Each organisation element in Chorn's framework can be described in terms of a mix of four logics: performance, administration, development and intimacy. These logics are related directly to the Myers-Briggs Type Indicator instrument principal axes, ST, SF, NT and NF.

The strategic alignment framework developed by Chorn does not extend to an exploration of how to go about an examination and adjustment of leadership behaviour to best respond to the strategic complexity of the functional responsibilities in the leadership role, and does not address the relationship between personality type and leadership focus. This research considers this relationship, and goes further by focusing on the other leadership behaviour preferences needed to focus optimally across Chorn's four logics, given an understanding of the personality type of the leader, the approach of the leader to manage a multiple focus, and the type of organisation being led.

It is the relationship between the personality type of the leader and the organisation type, particularly in terms of alignment or fit, that is considered in this study as a part of what constitutes leadership focus.

\section{Leadership Capacity for a Multiple Focus}

Increasing stakeholder expectations increases the need for the strategic leader to hold a multiple focus. Gabel (2002) suggested that successful leaders nearly always function from a middle position in which they understand the internal contexts of subordinates as well as those of more senior management and other stakeholders. Patterson et al. (1996) argued that a common denominator amongst all leaders is the need to find a way to keep the competing demands of stakeholders in balance. A variety of tools and aids have been suggested to assist leaders to manage a multiple focus in the face of complex demands and choices (Schwering, 2003). A multiple focus is particularly necessary in times of change, for the execution of strategic plans, re-engineering efforts, quality improvement programmes, mergers and acquisitions and other major implementation efforts

\section{RESEARCH DESIGN}

Research Approach

The following methodological approach was used in the design of this study:

\section{Multiple Phases}

A multiple phase approach was used to allow for the inclusion of a pilot study and to contribute to the generation and fleshing out of research concepts, the operationalising of key variables, and the testing of research concepts in the target population. This approach has enabled an understanding of the research area to be built up in stages.

\section{Methodological Triangulation}

Methodological triangulation was considered relevant for this study, given the complexity of the research variables. The research design combined both quantitative and qualitative data sources in response to the challenge of operationalising key complex variables within the study.

\section{Survey-based, primarily quantitative methodology}

Survey construction allowed for responses that can be analysed quantitatively. Open-ended questions were also included at the end of the survey to capture thoughts, opinions and other suggestions.

\section{Participants}

The target population was the group of managers and leaders attending university business school executive education programmes at Wits Business School (WBS), University of Witwatersrand, in South Africa. These programmes are held in either Johannesburg or Cape Town as public or in-company events.

In the study period, the population of delegates attending programmes numbered approximately 800 . Of these, a target of $25 \%$ or 200 respondents formed the sample for the study. This sample size was slightly larger than that required by standard guidelines for determining sample sizes, based on Stoker (1981), in Roodt (2004). Stoker's sampling ratio for a population of 500 is $20 \%$, and for a population of 1,000 is $14 \%$. The population was stratified on the basis of the participant's current management development interest, indicated by the topic of the management programme being attended.

\section{Measuring Instruments/methods of data gathering}

The independent variable, personality type, was assessed via the Myers-Briggs Type Indicator instrument, an instrument that is widely validated. The dependant variable, leadership focus, was assessed via the Leadership Focus Questionnaire (LFQ), developed by the author.

The LFQ is a survey instrument designed to discover more about the relationship between personality type and 
leadership focus. It consists of three sections. Section A contains 41 quantitative questions covering various elements of the three theoretical hypotheses on leadership focus, and 5 placebo questions. The questions are answered on a Likert scale. Section B consists of a number of open-ended qualitative questions on leadership focus, designed to capture other thoughts and feelings that the respondent may want to share. Section C requests demographic and work-related information from the respondent.

A content analysis was applied to the qualitative responses to Section B of the LFQ.

\section{Procedure}

The LFQ was first applied in a pilot study, where the logistics of survey administration were tested, in terms of time taken for completion (acceptable to the participants, at 2030 minutes), ease of use, and clarity of questions (also found to be acceptable, based on user questions and comments). The pilot study was conducted in June 2004. The main study was conducted over the period August to November 2004. In both studies, Form $\mathrm{M}$ of the Myers-Briggs Type Indicator Instrument was administered first, followed by the LFQ.

\section{Statistical Analysis}

A process of factor analysis was applied to the data generated from the themes identified in the literature associated with leadership focus. The derived leadership focus factors were tested against the Myers-Briggs Type Indicator attitudes, rocesses, functions and types to identify differences in response based on personality type. The following steps were taken:

1) Of the forty-six questions in Section A of the LFQ considered for inclusion in the factor analysis, all were answered on a six-point Likert scale (with one exception: Question 46, addressing an aspect of organisation type, was asked on a four-point scale since this best approximated findings from related research on organisation type; it was eliminated from the factor analysis, to be addressed separately). Five placebo questions were eliminated. Forty questions were retained for the first-order factor analysis.
2) In the first-order (orthogonal) analysis, a further eight questions were omitted due to a low MSA (measure of sampling adequacy) $<0,6$.

3) The remaining thirty-two questions yielded 10 factors. Of these, 5 were meaningful groupings with Cronbach Alpha values of $>0,6$ but $<0,7$. These were named and retained for further analysis. The other 5 had Alpha values $<0,6$, and were discarded.

4) A second-order (oblique) analysis was then applied. Three first-order factors were excluded due to low MSA values $<0,6$, and twenty-six questions were retained. Two second-order factors were identified, both with Cronbach Alpha values > 0,7 . One factor contained 12 questions, the other 14 questions.

5) The first- and second-order retained factors are displayed in Table 1 . The relationships between the factors, the three primary hypotheses used to construct the LFQ, and the LFQ questions are displayed in Tables 2, 3, and 4 .

TABLE 1

FiRST AND SECOND ORDER FACTORS

\begin{tabular}{|c|c|c|c|}
\hline $\begin{array}{l}\text { Second-order } \\
\text { Factors }\end{array}$ & $\begin{array}{l}\text { First-order } \\
\text { Factors }\end{array}$ & & \\
\hline $\begin{array}{l}\underline{2}^{\text {nd_order factor } 1} \\
\text { Challenge with } \\
\text { Leadership Focus }\end{array}$ & $\begin{array}{l}\underline{1}^{\text {st }- \text { order factor } 4} \\
\text { Stress of Balancing } \\
\text { Competing Demands }\end{array}$ & & \\
\hline $\begin{array}{c}(37,666 \% \text { of } \\
\text { variation explained })\end{array}$ & $\begin{array}{c}(4,878 \% \text { of } \\
\text { variation explained })\end{array}$ & & \\
\hline $\begin{array}{l}\underline{2}^{\text {nd-order factor } 2} \\
\text { Comfort with } \\
\text { Leadership Focus }\end{array}$ & $\begin{array}{l}1^{\text {st-order factor } 1} \\
\text { Comfort with } \\
\text { Organisation Fit }\end{array}$ & $\begin{array}{c}1^{\text {st-order factor } 2} \\
\text { Future and Strategic } \\
\text { Thinking }\end{array}$ & $\begin{array}{c}\underline{1}^{\text {st-order factor } 5} \\
\text { Communicating } \\
\text { Strategy to } \\
\text { Stakeholders }\end{array}$ \\
\hline $\begin{array}{c}(14,339 \% \text { of } \\
\text { variation explained })\end{array}$ & $\begin{array}{c}(16,451 \% \text { of } \\
\text { variation explained })\end{array}$ & $\begin{array}{c}(8,924 \% \text { of } \\
\text { variation explained })\end{array}$ & $\begin{array}{c}(4,648 \% \text { of } \\
\text { variation explained })\end{array}$ \\
\hline \multicolumn{4}{|l|}{$\begin{array}{l}\text { Demands of External } \\
\text { Stakeholders }\end{array}$} \\
\hline $\begin{array}{c}(6,176 \% \text { of } \\
\text { variation explained })\end{array}$ & & & \\
\hline
\end{tabular}

TABLE 2

RELATIONSHIP BETWEEN CHALLENGE WITH LEADERSHIP FOCUS AND THE LFQ

\begin{tabular}{|c|c|c|c|}
\hline $2^{\text {nd }}$-order Factor & $1^{\text {st }- \text { order Factor }}$ & LFQ Questions & $\begin{array}{l}\text { Theory-based Preliminary } \\
\text { Factor }\end{array}$ \\
\hline \multirow[t]{12}{*}{$\begin{array}{l}\text { Challenge with } \\
\text { Leadership Focus }\end{array}$} & $\begin{array}{l}\text { Stress of Balancing } \\
\text { Competing Demands }\end{array}$ & $\begin{array}{l}\text { 30. I take on too much and cannot do justice to everything; some priorities are } \\
\text { not properly dealt with by me (variable 19) }\end{array}$ & $\begin{array}{l}\text { Balancing internal and } \\
\text { external priorities }\end{array}$ \\
\hline & & $\begin{array}{l}\text { 16. I find the challenge of dealing with the competing and conflicting demands } \\
\text { of different stakeholders stressful and draining of my energy (variable 31) }\end{array}$ & $\begin{array}{l}\text { Approach to managing a } \\
\text { multiple focus }\end{array}$ \\
\hline & & $\begin{array}{l}\text { 32. I tend to prefer to address some important issues at the expense of others in } \\
\text { my current role (variable 12) }\end{array}$ & $\begin{array}{l}\text { Balancing internal and } \\
\text { external priorities }\end{array}$ \\
\hline & & $\begin{array}{l}\text { 1. My colleagues would say that I am good at balancing my time across competing } \\
\text { priorities (variable } 14 \text { - inverted) }\end{array}$ & $\begin{array}{l}\text { Balancing internal and } \\
\text { external priorities }\end{array}$ \\
\hline & & $\begin{array}{l}\text { 24. I prefer a working lunch at my desk or with staff than dining with } \\
\text { prospective customers (variable } 3 \text { ) }\end{array}$ & $\begin{array}{l}\text { Balancing internal and } \\
\text { external priorities }\end{array}$ \\
\hline & & 11. Urgent rather than important tasks tend to take up my time (variable 17) & $\begin{array}{l}\text { Balancing internal and } \\
\text { external priorities }\end{array}$ \\
\hline & & $\begin{array}{l}\text { 31. I tend to give priority to issues that are mostly different from those given } \\
\text { priority to by the organisation (variable } 26 \text { ) }\end{array}$ & Fit with organisation type \\
\hline & & $\begin{array}{l}\text { 36. In our organisation we only reveal new strategic initiatives to staff when } \\
\text { they are being implemented (variable } 42 \text { ) }\end{array}$ & $\begin{array}{l}\text { Approach to managing a } \\
\text { multiple focus }\end{array}$ \\
\hline & & $\begin{array}{l}\text { 37. Increasing due diligence requirements has resulted in less time for staff } \\
\text { management (variable 9) }\end{array}$ & $\begin{array}{l}\text { Balancing internal and } \\
\text { external priorities }\end{array}$ \\
\hline & & $\begin{array}{l}\text { 39. More of my time is taken up with internal issues than marketing and } \\
\text { sales issues (variable 1) }\end{array}$ & $\begin{array}{l}\text { Balancing internal and } \\
\text { external priorities }\end{array}$ \\
\hline & & $\begin{array}{l}\text { 43. My personal style is significantly different from the culture of the } \\
\text { organisation (variable 23) }\end{array}$ & $\begin{array}{l}\text { Fit with organisation } \\
\text { type }\end{array}$ \\
\hline & & $\begin{array}{l}\text { 7. I am often frustrated by my organisation giving priority to the wrong kinds } \\
\text { of issues to the allocation of time, resources \& executive focus (variable } 27 \text { ) }\end{array}$ & $\begin{array}{l}\text { Fit with organisation } \\
\text { type }\end{array}$ \\
\hline
\end{tabular}


TABLE 3

RELATIONSHIP BETWEEN COMFORT WITH LEADERSHIP FOCUS AND THE LFQ

\begin{tabular}{|c|c|c|c|}
\hline $2^{\text {nd }}$-order Factor & $1^{\text {st_order Factor }}$ & LFQ Questions & $\begin{array}{l}\text { Theory-based Preliminary } \\
\text { Factor }\end{array}$ \\
\hline \multirow[t]{14}{*}{$\begin{array}{l}\text { Comfort with } \\
\text { Leadership Focus }\end{array}$} & \multirow[t]{4}{*}{$\begin{array}{l}\text { Comfort with } \\
\text { Organisation Type }\end{array}$} & $\begin{array}{l}\text { 35. In attending to pressing issues I adjust my focus to best fit with the priority } \\
\text { given by the organisation (variable } 25 \text { ) }\end{array}$ & Fit with organisation type \\
\hline & & $\begin{array}{l}34 . \text { I work in a team environment where we allocate responsibility for pressing } \\
\text { issues in a way that ensures that the most important issues are addressed } \\
\text { (variable 18) }\end{array}$ & $\begin{array}{l}\text { Balancing internal and } \\
\text { external priorities }\end{array}$ \\
\hline & & $\begin{array}{l}\text { 40. My organisation can be best described as having a well developed process } \\
\text { improvement focus (variable } 21 \text { ) }\end{array}$ & Fit with organisation type \\
\hline & & $\begin{array}{l}\text { 20. I make a point of encouraging two-way communication sessions with staff } \\
\text { about strategic initiatives (variable 39) }\end{array}$ & $\begin{array}{l}\text { Approach to managing a } \\
\text { multiple focus }\end{array}$ \\
\hline & \multirow[t]{5}{*}{$\begin{array}{l}\text { Focus on Future and } \\
\text { Strategic Thinking }\end{array}$} & $\begin{array}{l}\text { 22. I try to match emerging opportunities in the market-place with the inherent } \\
\text { potential of the organisation (variable } 36 \text { ) }\end{array}$ & $\begin{array}{l}\text { Approach to managing a } \\
\text { multiple focus }\end{array}$ \\
\hline & & $\begin{array}{l}\text { 23. I often think about future challenges and opportunities we need to prepare } \\
\text { for in the organisation (variable } 32 \text { ) }\end{array}$ & $\begin{array}{l}\text { Approach to managing a } \\
\text { multiple focus }\end{array}$ \\
\hline & & 15. I enjoy the challenge of dealing with multiple issues (variable 30 ) & $\begin{array}{l}\text { Approach to managing a } \\
\text { multiple focus }\end{array}$ \\
\hline & & $\begin{array}{l}\text { 21. I make sure that I balance my time appropriately across operational and } \\
\text { competitive issues (variable 11) }\end{array}$ & $\begin{array}{l}\text { Balancing internal and } \\
\text { external priorities }\end{array}$ \\
\hline & & $\begin{array}{l}\text { 3. I allocate sufficient time to internal and external stakeholders associated with } \\
\text { the organisation (variable } 28 \text { ) }\end{array}$ & $\begin{array}{l}\text { Approach to managing a } \\
\text { multiple focus }\end{array}$ \\
\hline & \multirow[t]{5}{*}{$\begin{array}{l}\text { Communicating } \\
\text { Strategy to Stakeholders }\end{array}$} & 17. I engage in regular feedback sessions with my staff (variable 38 ) & $\begin{array}{l}\text { Approach to managing a } \\
\text { multiple focus }\end{array}$ \\
\hline & & $\begin{array}{l}\text { 12. I keep everyone informed about those strategic initiatives under my control } \\
\text { (variable } 37 \text { ) }\end{array}$ & $\begin{array}{l}\text { Approach to managing a } \\
\text { multiple focus }\end{array}$ \\
\hline & & 18. I try to develop each staff member to his/her full potential (variable 33 ) & $\begin{array}{l}\text { Approach to managing a } \\
\text { multiple focus }\end{array}$ \\
\hline & & $\begin{array}{l}\text { 41. I tend to focus on those job responsibilities that interest me) variable } \\
15 \text { - inverted) }\end{array}$ & $\begin{array}{l}\text { Balancing internal and } \\
\text { external priorities }\end{array}$ \\
\hline & & $\begin{array}{l}\text { 2. I have been criticised for not paying attention to certain important aspects of } \\
\text { the business (variable } 13 \text { - inverted) }\end{array}$ & $\begin{array}{l}\text { Balancing internal and } \\
\text { external priorities }\end{array}$ \\
\hline
\end{tabular}

TABLE 4

RELATIONAHIP BETWEEN DEMANDS OF EXTERNAL STAKEHOLDERS AND THE LFQ

\begin{tabular}{lll}
\hline 2nd-order Factor & LFQ Questions \\
\hline N/A & $\begin{array}{l}\text { Demands of External } \\
\text { Stakeholders }\end{array}$ & $\begin{array}{l}\text { 33. I tend to spend more time addressing issues external to the organisation } \\
\text { (e.g. competitive, legislative, global, technological factors) than internal to the } \\
\text { organisation (those concerning staff, roles, processes, operations) (variable 24) } \\
\text { 42. My personal performance is influenced more by my ability to address the } \\
\text { needs of external stakeholders than those of staff and internal efficiencies } \\
\text { (variable 8) } \\
\text { 29. I spend more time with external stakeholders than with staff (variable 2) }\end{array}$ \\
&
\end{tabular}

6) For the purposes of comparing LFQ responses across the 16 Myers-Briggs Type Indicator instrument types, each type was coded into a table in a sequence consistent with other studies on type (Kirby, 1997, pp22-25). The table, along with the distribution of type responses for this study, is shown in Table 5.

TABLE 5

DISTRIBUTION OF MAIN STUDY MBTI TYPES

\begin{tabular}{lccccc}
\hline & \multicolumn{2}{c}{ Sensing types } & \multicolumn{2}{c}{ Intuitive types } & \\
\hline Introverts & ISTJ & ISFJ & INFJ & INTJ & Introverts \\
& $13,2 \%$ & $1,5 \%$ & $2,0 \%$ & $9,8 \%$ & \\
& ISTP & ISFP & INFP & INTP & \\
& $3,4 \%$ & $0,5 \%$ & $3,9 \%$ & $8,3 \%$ & \\
Extravertes & ESTP & ESFP & ENFP & ENTP & Extraverts \\
& $3,9 \%$ & $0,0 \%$ & $6,3 \%$ & $11,2 \%$ & \\
& ESTJ & ESFJ & ENFJ & ENTJ & \\
& $17,6 \%$ & $1,5 \%$ & $2,9 \%$ & $13,7 \%$ & \\
\hline
\end{tabular}

Representativeness of Sample

While the sample frame excluded a number of specialist programme topics offered by WBS that were either not being offered during the survey period or did not fall into one of the five defined strata for programme topics, the five strata in the sample (Certificate Programmes, General Management, Finance, Human Resources and Marketing) do cover a wide range of executive programme topics, and are arguably the primary areas of interest and concern for executives, based on 2004 attendance figures $(82 \%$ of all WBS delegates in Cape Town attended programmes that fell within the five strata defined in this study).

The sample only included delegates on WBS programmes, although there are a number of business school executive education providers in South Africa. WBS may be considered to be the most representative provider of executive education in the country, in that it offers the largest selection of programmes relative to other providers, and was the only South African business school to be ranked by the UK-based Financial Times in its top 45 executive education programme provider rankings in 2003 (Bradshaw, 2003). 
In order to confirm that the sample of executives participating in this study follow a similar pattern to that observed in other studies, a cross-tabulation over nine international studies (reported by Kirby, 1997), along with the sample from this study, was conducted. Two chi-square based measures of association were applied, Phi and Cramer's V. For both measures of association, the effect size had a value of zero, indicating that there are no statistically significant differences in the distribution of Myers-Briggs Type Indicator instrument types between this study and the other studies of managers, executives and leaders. This finding further strengthened the representativeness of this study sample.

\section{Bias in Sample}

Given the range of organisations represented and the seniority levels of executives participating in the study, it is prudent to consider the possibility of bias manifesting in the sample, in that: 1) not all organisations invest in sending their executives on education programmes; the sample may therefore carry some bias towards executives employed by those organisations who do; and 2) the respondents were mostly middle to senior level managers in their respective organisations; although it is these managers who are predominantly in leadership roles in South African businesses, they are not necessarily representative of executives at even more senior levels of management. Generalisations made from the research propositions should therefore be treated with caution. Further study amongst executives from a broader range of organisations and at more senior levels in their organisations is recommended.

\section{RESULTS}

\section{LFQ Relationship with MBTI Attitudes and Processes}

1.4.8. The five LFQ first-order factors and two second-order factors, seven factors in all, were correlated against the four attitudes (Extraversion, Introversion, Judging and Perceiving), and the four processes (Sensing, Intuition, Thinking and Feeling) of the Myers-Briggs Type Indicator instrument using the Pearson Correlation Coefficient to determine any statistically significant relationships.

In all instances, the hypothesised proposition was that there is a statistically significant relationship between each LFQ factor and Myers-Briggs Type Indicator instrument attitude or process, as follows:

Ho: There is no relationship between the LFQ first-order factor $(\times 1 . . \times 5)$ or second-order factor $(\times 6 . . \times 7)$ and the MyersBriggs Type Indicator instrument attitude or process (E, I, J, P, S, N, T, F)

H1: There is a statistically significant relationship between the LFQ first-order factor $(\times 1 . . \times 5)$ or second-order factor $(\times 6 . . \times 7)$ and the Myers-Briggs Type Indicator instrument attitude or process (E, I, J, P, S, N, T, F)

The notation used in the hypotheses (e.g. " $(\times 1 . . \times 5)$ " above) requires that the hypothesis be considered for each of the variables included in the hypothesis. For example, the null and alternate hypotheses above apply for each of the five first-order factors and two second-order factors.

The research proposition, $\mathrm{H} 1$, may be accepted at the 0,01 level of significance in the following instances:

1) First-order factor 4, 'Stress of Balancing Competing Demands', is positively correlated to I and inversely correlated to E

2) Second-order factor 1, 'Challenge with Focus in the Leadership Role', is positively correlated to I and inversely correlated to $\mathrm{E}$

3) Second-order factor 2, 'Comfort with Focus in the Leadership Role', is inversely correlated to F

The research proposition, H1, may also be accepted at the 0,05 level of significance in the following instances:
1) First-order factor 2, 'Future and Strategic Thinking', is positively correlated to E, and inversely correlated to I

2) First-order factor 4, 'Stress of Balancing Competing Demands', is positively correlated to $\mathrm{F}$ and inversely correlated to $\mathrm{T}$

3) First-order factor 5, 'Communicating Strategy to Stakeholders', is positively correlated to E and inversely correlated to I

4) Second-order factor 1, 'Challenge with Focus in the Leadership Role', is positively correlated to F and inversely correlated to $\mathrm{T}$

5) Second-order factor 2, 'Comfort with Focus in the Leadership Role', is positively correlated to E, T, and J, and inversely correlated to I and P

In all other instances, the null hypothesis, Ho, must be accepted with regard to the relationship between LFQ factors and MyersBriggs Type Indicator instrument attitudes and processes.

\section{Measure of Sample Effect (Eta)}

While the Pearson Correlation Coefficients provide an indication of statistical significance that allow for the rejecting of the null hypothesis, Eta takes the effect of sample size out of the measure for significance, and provides an indication of practical significance of differences in the sample. Given that the sample size in this study was high in terms of influencing statistical significance, Eta values have also been computed for the five first-order and two second-order LFQ factors in relation to the Myers-Briggs Type Indicator instrument attitudes and processes.

An Eta value of 0 indicates 'no effect'; $0<$ Eta $<0,3$ indicates a 'small effect'; $0,3<=$ Eta $<0,5$ indicates a 'medium effect'; and Eta $\Rightarrow 0,5$ indicates a 'large effect'. In all instances, the Eta values of attitude and process dichotomies in relation to the LFQ factors indicate a small effect, as is illustrated in Table 6 below.

TABLE 6

ETA VALUES FOR MBTI ATTITUDES AND PROCESSES

\begin{tabular}{lccccc}
\hline LFQ Factor & E-I & S-N & T-F & J-P \\
\hline Comfort with organisation fit & 0,057 & 0,066 & 0,062 & 0,062 \\
Future and strategic thinking & 0,177 & 0,105 & 0,044 & 0,054 \\
Demands of external stakeholders & 0,062 & 0,084 & 0,019 & 0,003 \\
Stress of balancing competing demands & 0,172 & 0,127 & 0,087 & 0,072 \\
Communicating strategy to stakeholders & 0,132 & 0,026 & 0,027 & 0,023 \\
Challenge with focus in the leadership role & 0,174 & 0,141 & 0,131 & 0,119 \\
Comfort with focus in the leadership role & 0,150 & 0,029 & 0,141 & 0,105
\end{tabular}

While all four Myers-Briggs Type Indicator instrument dichotomies have a small effect in response to each of the LFQ factors, the Extravert (E) - Introvert (I) attitude dichotomy has a bigger effect than the other three dichotomies. Thus the practical significance of differences in responses to leadership focus between $\mathrm{E}$ and $\mathrm{I}$ is greater han that for similar differences in responses between $\mathrm{S}$ and $\mathrm{N}$, $\mathrm{T}$ and $\mathrm{F}$, and $\mathrm{J}$ and $\mathrm{P}$.

\section{Analysis of Organisation Responsiveness to External} Environment

LFQ Question 46 asks about the responsiveness of the organisation to changes in the external environment, using a four-point scale. This question contributes to information about leadership fit with organisation type. A four point scale was used, in contrast to the six-point Likert scale applied to the other questions in the LFQ, because it captures more readily the organisation type logics defined in other related research, such as Chorn $(2004,1987)$. The four logic categories defined by Chorn (Performing or Pragmatic; Administrative; Developmental or Divergent; Intimate or Integrative) also define four logical 
divisions on the sigmoid curve often associated with the lifecycle of an industry or organisation (Chorn, 2004; Roxburgh and Huyett, 2002). See Figure 4.

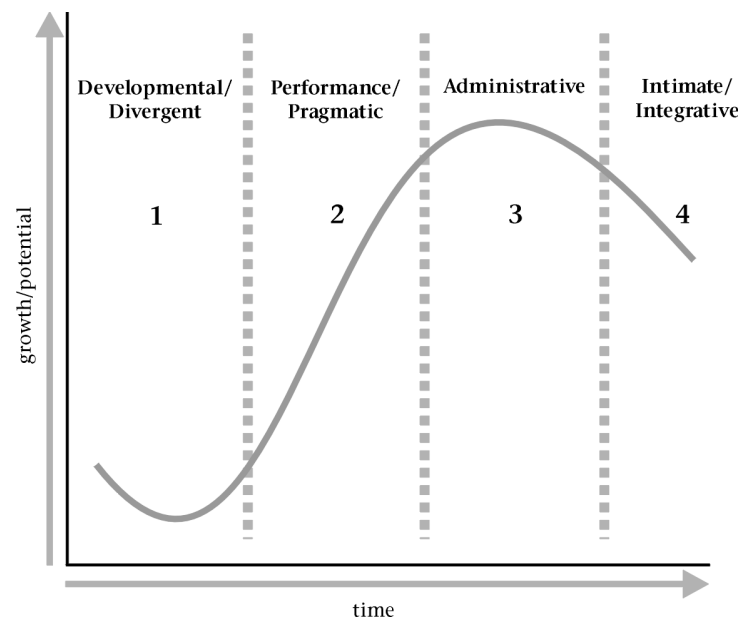

Figure 4: Organisation logic across life-cycle

The four points of the scale used for question 46, along with the percentage distribution of responses from this study, are as follows:

1) A Market Innovator \& Shaper (Divergent): $42,5 \%$

2) A Quick Adapter of New Trends (Pragmatic): $33 \%$

3) A Reluctant Follower of Only Well Proven Trends (Administrative): 18\%

4) Mostly Resistant to any Form of Innovation or Change (Integrative): 6,5\%

Figure 4 illustrates the theoretical overlay of a typical life-cycle curve with Chorn's organisation logics and the four points of the scale used for Question 46. Given the small representation of responses in category four of Question 46, it was merged with category three for the purposes of a chi-square analysis of the responses to this question in relation to Myers-Briggs Type Indicator instrument attitudes and processes.

Two chi-square based measures of association were applied, Phi and Cramer's V, for each of the four dichotomies, E-I, S-N, T-F and J-P. For both measures of association, the effect size was small or very small, indicating that there are no strong or even medium level measures of association for this question, based on the four Myers-Briggs Type Indicator instrument dichotomies.

\section{LFQ Relationship with MBTI Axes}

The five LFQ first-order factors and two second-order factors were correlated against the four axes (these are the two-element combinations of the two process dichotomies: NT, NF, ST, and $\mathrm{SF}$ ) of the Myers-Briggs Type Indicator instrument to determine any statistically significant relationships using the Pearson Correlation Coefficient. In all instances, the hypothesised proposition was that there is a statistically significant relationship between each LFQ factor and Myers-Briggs Type Indicator instrument axis, as follows:

Ho: There is no relationship between the LFQ first-order factor $(\times 1 . . \times 5)$ or second-order factor $(\times 6 . . \times 7)$ and the Myers-Briggs Type Indicator instrument axis (NT,ST, NF, SF)

H1: There is a statistically significant relationship between the LFQ first-order factor $(\times 1 . . \times 5)$ or second-order factor $(\times 6 . . \times 7)$ and the Myers-Briggs Type Indicator instrument axis (NT,ST, NF, SF).

The research proposition, H1, may be accepted at the 0,01 level of significance in the following instances:

1 First-order factor 2, 'Future and Strategic Thinking', is positively correlated to NT and inversely correlated to SF.
The research proposition, H1, may also be accepted at the 0,05 level of significance in the following instances:

1) Second-order factor 1, 'Challenge with Focus in the Leadership Role', is positively correlated to NF and inversely correlated to ST

2) Second-order factor 2, 'Comfort with Focus in the Leadership Role', is positively correlated to NT and inversely correlated to SF

In all other instances, the null hypothesis, Ho, must be accepted with regard to the relationship between LFQ factors and MyersBriggs Type Indicator instrument axes.

\section{LFQ Relationship with MBTI Types}

The respondents were each assigned one of sixteen possible Myers-Briggs Type Indicator types, based on their completion of Form M. Of these sixteen type categories, only six had a sufficiently high sample weighting (either $10 \%$ or more of the study sample, or at least 18 respondents) to warrant inclusion in an ANOVA analysis.

The six included types (percentage of study sample in brackets) are: ISTJ $(13,2 \%)$; INTJ $(9,8 \%)$; INTP $(8,3 \%)$; ENTP $(11,2 \%) ; \operatorname{ESTJ}(17,6 \%) ;$ and ENTJ $(13,7 \%)$. These six types are typically most prevalent in business management and leadership studies (Kirby, 1997). Four of the six types, ISTJ, ENTP, ESTJ and ENTJ were each selected by more than $10 \%$ of the total sample.

The ANOVA was applied twice for each of the five firstorder-factors and two second-order factors of the LFQ, first to the six qualifying Myers-Briggs Type Indicator types, and then to the smaller set of four qualifying MyersBriggs Type Indicator types, to determine statistically significant differences in factor response by Myers-Briggs Type Indicator type.

For the first application of the ANOVA to the six qualifying types, the null hypothesis was accepted for all LFQ factors. For the second application of the ANOVA to the smaller set of four qualifying types, the hypothesised proposition was that there are statistically significant differences between Myers-Briggs Type Indicator types in relation to each LFQ factor, as follows:

Ho: There is no difference between Myers-Briggs Type Indicator qualifying types (x1..x4) for the LFQ first-order factor $(\times 1 . . \times 5)$ or for the LFQ second-order factor $(\times 6 . . \times 7)$

H1: There are statistically significant differences between Myers-Briggs Type Indicator qualifying types $(\times 1 . . \times 4)$ for the LFQ first-order factor $(\times 1 . . \times 5)$ or for the LFQ secondorder factor $(\times 6 . . \times 7)$

The research proposition, H1, may be accepted at the 0,05 level of significance for differences between the four qualifying types for the LFQ First-order factor, 'Future and Strategic Thinking'.

\section{Relationship Between Strata and LFQ}

The five strata within the stratified sample were analysed for statistically significant difference in relation to each of the two second-order LFQ factors.

The Eta values for these second-order factors were as follows:

- Second-order factor 1: Challenge with Focus in the Leadership Role: Eta $=0,134$

- Second-order factor 2: Comfort with Focus in the Leadership Role: $\mathrm{Eta}=0,219$

In both instances, the Eta value suggests a small effect size. There are small differences in responses to these LFQ factors based on the stratification of the sample in this study.

Incorporation of Qualitative Responses from the LFQ

For all four questions, the clear majority of responses were framed in positive terms. A content analysis of the answers reveals that only 
- $27 \%$ of the respondents chose to mention reactive issues or people difficulties among the issues regularly competing for their attention (Question 47)

- $10 \%$ of the respondents chose to identify people or other difficulties in going about prioritising issues that needed to be addressed (Question 48)

- $9 \%$ of the respondents described some aspect of difficulty in managing situations where there are too many issues competing for attention (Question 49)

- $35 \%$ of the respondents suggested that the fit between themselves and their organisation was less than ideal (Question 50)

In order to discern differences between the Myers-Briggs Type Indicator instrument types and the qualitative responses to these LFQ questions, the content analysis focused on the minority of responses that expressed some dissatisfaction or negative feeling across the four dichotomies. The details of this analysis are described for each of the four questions below.

\section{Content Analysis}

Questions 47-50 of the LFQ were subjected to a qualitative content analysis, as follows:

Question 47 of the LFQ asked the question 'What kinds of issues compete for your attention on a regular basis?' The content analysis suggests that Introverted (I), Thinking (T) and Perceiving $(\mathrm{P})$ types in this study report more difficulty in dealing with reactive staff issues ("Regular moaning and groaning" - ISTJ; "Staff issues - personal and work related" INTP; "Staff problems" - ENTP; "Issues in the team, e.g. New Business Consultants perhaps working on the same deal" ESTJ), and that Sensing (S) types report more difficulty in dealing with reactive operational issues other than staff issues ("Frequent interruptions by customers" - ESTJ; "Internal processes and restrictions" - ESTP).

Question 48 of the LFQ asked the question 'How do you go about prioritising which issues to address?' The content analysis suggests that Intuitive (N), Feeling (F) and Perceiving (P) types in this study report more difficulty in prioritising in general ("Line partnership takes top priority and can sometimes (most often) disrupt my plans for the day" - ENFP; "What the boss wants" - ENTP; "I put out the biggest fires first" - ESTP; "External and internal demands take priority to planning" - INFP).

Question 49 of the LFQ asked the question 'How do you manage situations where there are too many issues competing for your attention?' No particular pattern of differences in response emerges across the four Myers-Briggs Type Indicator instrument dichotomies.

Question 50 of the LFQ asked the question 'How would you describe the fit between yourself and your organisation?' The content analysis suggests that Introverted (I), Intuitive (N), Feeling ( $\mathrm{F}$ ) and Perceiving (P) types in this study report a greater lack of fit between themselves and their organisation ("At times out of line; don't always agree with the autocratic style" - ENFJ; "At strategy execution level, the fit is poor" ENTP; "I am values-driven in my approach to work and interacting with the culture and I find this sometimes conflicts with the current status quo" - ESFP; "I am too wild for the company culture" - ESTP; "I am a mismatch for the organisation in its current state, but I represent the desired future state" - INFJ; "The company focus is performance and administration, mine is performance and building relationships" - INFP; "Don't agree with some of the internal political agendas of late" - INTJ; "So far no fit, but still working on it. Only the ideal is talked about." - ISFP; "The lack of speed in implementation is my major frustration" - ISTJ).

\section{DISCUSSION}

Personality Type and Leadership Focus Factors

1.8.2.1.2. In relation to the derived leadership focus factors, a number of the differences in response between personality types are worthy of discussion.

\section{Approach to Future and Strategic Thinking}

There is a statistically significant relationship between the personality type of a leader and his or her approach to future and strategic thinking. This is evident in relation to the attitude dimension E-I, and in relation to the axes NT and SF, where E and NT are positively correlated and I and SF are negatively correlated to this factor. While the differences in response between NT and SF may be easily explained (N and T may be more naturally drawn to a logical consideration of big picture possibilities while $\mathrm{S}$ and $\mathrm{F}$ may be better attuned to the values and specifics of the here and now), the differences in response between $\mathrm{E}$ and $\mathrm{I}$ are not obvious. It may be that Extraverts are more comfortable than Introverts in engaging with external stakeholders and are thus more likely to discover new trends and future opportunities. There, however, many other avenues for Introverted types to relate positively to future and strategic thinking.

\section{Dealing with the Stress of Competing Demand}

There is a statistically significant relationship between the personality type of a leader and his or her approach to dealing with the stress of competing demands. This is evident in relation to the process dimension T-F, where $\mathrm{F}$ is positively correlated and $\mathrm{T}$ is negatively correlated to this factor. The differences in response between the Feeling and Thinking processes may be explained in terms of Thinking types applying logical, rational criteria to prioritise competing demands, while Feeling types are more likely to be attuned to competing values that cannot be easily prioritised. This difference can be explained in terms of the relative ease that Extraverts may have over Introverts in engaging others to assist in addressing competing demands.

The qualitative content analysis supports the statistical findings for this factor, suggesting that Intuitive, Feeling, and Perceiving types in this study report more difficulty in prioritising in general ("Line partnership takes top priority and can sometimes (most often) disrupt my plans for the day" - ENFP; "I put out the biggest fires first" - ESTP; "External and internal demands take priority to planning" - INFP).

\section{Communicating Strategy to Stakeholders}

There is a statistically significant relationship between the personality type of a leader and his or her approach to communicating strategy to stakeholders. This is evident in relation to the attitude dimension E-I, where $\mathrm{E}$ is positively correlated and I is negatively correlated to this factor. These differences in response can be explained by the likelihood that Extraverts are more comfortable than are Introverts in communicating with others, whether it be with internal or external stakeholders.

\section{Challenge with Focus in the Leadership Role}

This second-order factor is comprised of the first-order factor, Stress of Balancing Competing Demands, and five other LFQ questions. There is a statistically significant relationship between the personality type of a leader and his or her approach to dealing with the challenges of focus in the leadership role. This is evident in relation to the attitude dimension E-I, where I is positively correlated and $\mathrm{E}$ is negatively correlated, and the NF-ST axes, where NF is positively correlated and ST is negatively correlated. The differences in response between $\mathrm{NF}$ and ST can be understood in that ST types are more likely to focus on the details and apply a logical rational approach to dealing with conflicting challenges, while NF types are more likely to focus on the big picture, and may not pay attention to 
the detailed challenges in the leadership role. NF types may find it more difficult to use logical rather than value-based processes for prioritising conflicting priorities. The E-I attitude differences may once again be explained by the relative ease of Extraverts, in contrast to Introverts, to engage others for assistance in addressing challenges with focus.

\section{Comfort with Focus in the Leadership Role}

This second-order factor is comprised of three first-order factors, Communicating Strategy to Stakeholders, Comfort with Organisation Fit, Future and Strategic Thinking, and two other LFQ questions. There is a statistically significant relationship between the personality type of a leader and his or her comfort with focus in the leadership role. This is evident in relation to the attitude dimension E-I, where $\mathrm{E}$ is positively correlated and I is negatively correlated, and the NT-SF axes, where NT is positively correlated and SF is negatively correlated. The differences in response between NT and SF can be understood in that SF types are more likely to attune to a detailed appreciation of relative, possibly vexing and competing, values of various aspects of the leadership role, while the NT function is more likely to want to logically attune to the big picture and lead the organisation forward in terms of logical possibilities. The E-I attitude differences are opposite to the first second-order factor, and can be explained similarly by the relative ease of an Extravert compared to an Introvert in engaging others to assist in realising the potential of the leadership role.

\section{Impact of Sample Stratification}

Stratified sampling provides a method for obtaining a greater degree of representativeness by ensuring that appropriate numbers of elements are drawn from homogeneous subsets of the population under review. In the case of this study, the five strata each represent executives with similar specific management development needs, and on this basis each of these strata form homogenous subsets. An ANOVA was used to test for between-strata effects on the two second-order factors.

A small practical effect was found, based on sample stratification, for both second-order factors. An Eta of 0,134 for Challenge with Focus in the Leadership Role, and 0,219 for Comfort with Focus in the Leadership Role confirms that management development subject choice is an indicator, albeit small, of how participating executives go about optimising leadership focus. Such effects may be due to different personality types preferring different management development topics, or having different approaches to optimising leadership focus, based on their different management development needs.

\section{Relating the Study to Previous Research}

This study introduces a rationale for why Extraverted types are more commonly found in leadership roles. Their comfort with the challenges of leadership focus, perhaps the most pressing and complex of leadership challenges, and their confidence in their ability to succeed in optimising their focus, contributes to an explanation of why Extraverted types, more than Introverted types, are likely to seek out and succeed in positions of leadership. This supports work by Kets de Vries (2001) that pointed to the prevalence of extraverted attitudes amongst organisation leaders in a study on their psychodynamic attributes.

While Fitzgerald and Kirby (1997) rightly acknowledged that a diversity of Myers-Briggs Type Indicator instrument types serves to assist organisations dealing with increasing internal complexity, this study demonstrates varying levels of comfort with the challenge of focus in the leadership role across the key Myers-Briggs Type Indicator instrument axes. NF types reported that they are more challenged by focus in the leadership role than are ST types, and NT types reported that they are more comfortable than are NF types with focus in the leadership role.
There is much disquiet about the view of Ramaprasad and Mitroff (1984, in Walck, 1997) that holds a privileged position for NT types, based on their superiority in conditions valuing strategic problem solving. While this study does not make a judgment on ability, it does also reveal a significantly greater propensity amongst NT types for future and strategic thinking than SF types. A comfort and preference for future and strategic thinking may lead NT types, more than other personality types, to engage in this kind of thinking more frequently, and thereby better enable them to realise their potential. Thus NT types may have some advantages over other types in optimising leadership focus in traditional organisational settings that favour these preferences.

Block (2003) suggested that transformational leadership has a greater impact on organisation culture than does transactional leadership. The findings from this study suggest that, regardless of (transformational or transactional) leadership style, Introverted, Intuitive, Feeling and Perceiving types are less likely to experience optimal fit with their organisation than are their opposite counterparts. It may be induced that personality types with these preferences are more likely to try to transform the organisation, given their more common experience of a lack of fit with the status quo. ESTJ personality types, more likely to experience a comfortable fit with organisation type, are also more likely to engage in transactional leadership behaviour, in terms of personality type preferences. In an environment of business that increasingly demands transformational behaviour, there is a more pressing need for leadership personality types with a propensity to transform their organisations. Yet this study suggests that these personality types are less likely to be as comfortable with stepping into the leadership role as are those types who are more inclined to transactional leadership. This finding highlights the need for organisational settings that are more flexible and adaptive, open to change, and welcoming of non-traditional leaders who will be more comfortable with engaging in transformational leadership.

\section{Recommendations for Organisation Leaders}

The findings of this study highlight a number of recommendations for organisation leaders in this regard. Firstly, an understanding of personality type is a first step to effective self-management in the leadership role. Secondly, without prejudice to any personality type, the organisation leader would be well served to consider which behaviour preferences associated with his or her personality type help to optimise focus in the leadership role, and which behaviour preferences may increase difficulty with leadership focus.

Extraverted types (in contrast to Introverted types) in this study of South African executives report:

1) a greater comfort with organisation fit

2) a greater preference for future and strategic thinking

3) less stress with balancing competing demands

4) a greater ease with communicating strategy to stakeholders,

5) a greater comfort and lesser challenge with focus in the leadership role.

The five sentiments above are also more commonly reported by Thinking types (in contrast to Feeling types), with the exception of communicating strategy to stakeholders, where no significant differences were found with this dichotomy. In the qualitative content analysis, Sensing and Judging types express a greater comfort with their fit with their organisations than do Intuitive and Perceiving types.

The recommendation for organisation leaders who may have Myers-Briggs Type Indicator instrument type preferences for Introversion, Intuition, Feeling or Perceiving, is to consider how they can give more attention to their less preferred behaviour for each of the associated dichotomies, to benefit from a greater comfort with the leadership focus factors defined in this study. Equally, it must be noted that these findings do 
not ascribe an optimal leadership focus to organisation leaders with Extravert, Sensing, Thinking and Judging type preferences in their reported personality types. The Myers-Briggs Type Indicator instrument measures preferences, not aptitudes or capabilities. All organisation leaders, regardless of personality type, have the opportunity to optimise their leadership focus through a conscious application of the requisite personality and behaviour attributes.

\section{Recommendations for HR Professionals}

The study findings present HR professionals with important challenges in relation to those high-potential leaders with preferences for Introversion and Feeling. A strategic HR development role would be assist such leaders to develop and balance their less preferred behaviours in order to find a more comfortable fit in dealing with the challenges of leadership focus, without letting go of the gift that their natural preference for Introversion and Feeling may bring to the leadership role. Equally, HR professionals need to encourage a more rounded set of behaviours that include more practice of Introversion (or introspection and reflection) and Feeling behaviours in those leaders who are comfortable with taking on the challenges of focus, who have a natural preference for Extraversion and Thinking.

\section{Limitations of this Research}

The limitations of this study are that: 1) the sample size and make-up is limited to South African executives attending management education programmes over a 6 month period in Cape Town and Johannesburg; 2) other tools for assessing personality are not included in the research design; 3) the research findings, while statistically significant in a number of instances, have a smaller practical significance, based on measures of sample effect, Eta; and 4) the research does not provide a practical formula or model for use by an individual leader to develop the skills for optimal strategic focus.

\section{Future Research Opportunities}

The relationship between personality type and the seven LFQ research factors provides a basis for extending Chorn's (2004) strategic alignment framework that considers personality type in relation to organisation type. By exploring those elements other than fit with organisation type necessary to optimise strategic alignment, Chorn's model may be enriched with additional dimensions. For example, the Extravert-Introvert dichotomy reveals a third dimensional element to the role of the leadership logic in influencing the internal and external environments associated with the organisation. Introverted leaders need to overcome their relatively lower desire to engage with internal and external stakeholders, or delegate effectively. There is, in the opinion of the author, scope to extend Chorn's model to include recognition of the role of the E-I attitude dichotomy and the J-P lifestyle dichotomy. The enhanced model would address more effectively the relationship between personality type and leadership focus that facilitates movement towards strategic alignment.

In relation to Extraversion versus Introversion, questions worthy of future research concern why organisations appear to favour Extraverted types in the leadership role, and what the implications may be for optimising leadership focus. Similarly with Thinking versus Feeling: why is there a strong preference for Thinking types amongst organisation leaders, and what are the implications for optimising focus?

\section{REFERENCES}

Barling, J., Slater, F., \& Kelloway E.K. (2000). Transformational leadership and emotional intelligence: an exploratory study. Leadership \& Organisation Development Journal, 21 (3).

Block, L. (2003). The leadership-culture connection: an exploratory investigation. Leadership \& Organisation Development Journal, 24 (6).
Boals K.B. \& Hooijberg R. (2001). Strategic leadership research: moving on. Leadership Quarterly, 11 (4).

Bridges, W. (2000). The Character of Organisations: Using personality type in organisation development. Palo Alto: DaviesBlack.

Carless, S.A. (2001). Assessing the discriminant validity of the Leadership Practices Inventory. Journal of Occupational and Organisational Psychology, 74 (2).

Carless, S.A. (2000). Assessing the discriminant validity of transformational leader behaviour as measured by the MLG (Multifactor Leadership Questionnaire). Journal of Occupational and Organisational Psychology, 71 (4).

Chorn, N.H. (2004). Strategic Alignment. Sydney: Richmond.

Chorn, N.H. (1987). The relationship between business-level strategy and organisational culture. Unpublished doctoral dissertation, University of Witwatersrand, Johannesburg, South Africa.

Collins, J. (2001). Good To Great. London: Random House.

Denton, M. \& Vloeberghs, D. (2003). Leadership challenges for organisations in the New South Africa. Leadership \& Organisational Development Journal, 24 (2).

Fitzgerald, C. (1997). The MBTI and Leadership Development: Personality and Leadership Reconsidered in Changing Times. In C. Fitzgerald \& L.K. Kirby (Ed.), Developing Leaders. Palo Alto: Davies Black.

Gregersen, H.B., Morrison, A.J. \& Black, J.S. (1998). Developing leaders for the global frontier. Sloan Management Review, 40 (1).

Hartley, J. (2002). Leading communities: capabilities and cultures. Leadership \& Organisation Development Journal, 23 (8).

Holt, D.T. \& Self, D.R. (2003). Facilitating organisational change: a test of leadership strategies. Leadership \& Organisation Development Journal, 24 (5).

Ingalls, J.D. (2000). Genuine and Counterfeit Leadership: the root causes and cures of human capital flight. Strategic Leadership, 28 (6).

Jung, C.G. (1923, 1971). Psychological Types. Princeton: Princeton University Press.

Kets de Vries, M.F.R. (2004). Dysfunctional Leadership. Berkshire: Sage.

Kets de Vries, M.F.R. (2001). The Leadership Mystique: a user's manual for the human enterprise. London: Prentice Hall.

Kets de Vries, M.F.R. (2001). Meditations on Happiness. London: Elbury Press.

Kets de Vries, M.F.R. (1993). Leaders, Fools, and Impostors. San Francisco: Jossey-Bass.

Kirby, L.K. (1997). Introduction: Psychological Type and the MyersBriggs Type Indicator. In C. Fitzgerald \& L.K. Kirby (Ed.). Developing Leaders. Palo Alto: Davies Black.

Klagge, J. (1996). Defining, discovering and developing personal leadership in organisations. Leadership \& Organisation Development Journal, 17 (5).

Kummerow, J.M. \& Olson, R.D. (1997). Using the MBTI Step II With Leaders and Managers. In C. Fitzgerald \& L.K. Kirby (Ed.). Developing Leaders. Palo Alto: Davies Black.

Lok, P. \& Crawford, J. (1990). The relationship between commitment and organisation culture, subculture, leadership style and job satisfaction in organisational change and development. Leadership \& Organisation Development Journal, 20 (7)

May, A. (2003). Developing management competencies for fastchanging organisations. Career Development International, $4(6)$.

McCauley, C.D. \& van Velsor, E. (2003). The Center for Creative Leadership Handbook of Leadership Development. (2nd ed.). San Diego: Center for Creative Leadership.

Myers, I.B., McCaulley, M.H., Quenk, N.L. \& Hammer, A.L. (1998). MBTI Manual: A Guide to the Development and Use of the Myers-Briggs Type Indicator. (3rd ed.). Palo Alto: Consulting Psychologists Press.

Patterson, K., Grenny, J., McMillan, R. \& Switzler, A. (1996). The Balancing Act. Cincinnati: Thomson Executive Press. 
Politis, J.D. (2003). QFD: the roles of various leadership styles. Leadership \& Organisation Development Journal, 24 (4).

Politis, J.D. (2001). The relationship of various leadership styles to knowledge management. Leadership \& Organisation Development Journal, 22 (8).

Roodt, G. (2004). Quantitative Research. Unpublished slide presentation. To doctoral students in Leadership in Performance And Change, Faculty of Economic And Management Science, University of Johannesburg, South Africa.

Schein, E. (1985). Organisational Culture \& Leadership. San Francisco: Jossey-Bass.

Shelton, C.K. \& Darling, J.R. (2001). The quantum skills model in management: a new paradigm to enhance effective leadership. Leadership \& Organisation Development Journal, 22 (6).
Shelton C.K., McKenna M.K., \& Darling J.R. (2002). Leading in the age of paradox: optimising behavioural style, job fit and cultural cohesion. Leadership \& Organisation Development Journal, 23 (7).

Sieff, G. \& Nurick, I. (1997). Practising strategic integration. Management, Australian Institute of Management Journal, January/February 1997.

Testa, M.R. (2002). A model for organisation-based 360-degree leadership assessment. Leadership \& Organisation Development Journal, 23 (5).

Walck, C.L. (1997). Using the Myers-Briggs Type Indicator instrument in Management and Leadership: A Review of the Literature. In C. Fitzgerald \& L.K. Kirby (Ed.). Developing Leaders. Palo Alto: Davies Black.

Weymes, E. (2003). Relationships, not leadership, sustain successful organisations. Journal of Change Management, 3 (4). 